\title{
Acute Mandibular Swelling Following Blunt Trauma
}

\author{
Rebecca James $^{\mathrm{a}}$, Marlene Soma ${ }^{\mathrm{b}}$, Anthony Leung ${ }^{\mathrm{c}}$, Stephen Sze Shing Teo ${ }^{\mathrm{a}}$, d, e, f(i)
}

\begin{abstract}
Submandibular trauma is rare, particularly in children or with an intact mandible. Clinical assessment of a child with a neck mass may need to be supplemented by diagnostic imaging. The optimal management of submandibular abscess is unclear, but an initially conservative approach is recommended. We report a case of a 10 -year-old girl with a blunt injury 2 days following a fall who presented with a fever and a large lateral neck swelling. Inflammatory markers were raised and antibiotics were commenced. A magnetic resonance imaging (MRI) scan led to an initial working diagnosis of a submandibular abscess. Over time she remained systemically well, and an ultrasound could not radiologically differentiate infection from a collection. The final diagnosis was a submandibular post-traumatic hematoma with a secondarily infected collection. The initial management and decision to transfer to a higher level of service was significantly aided by the availability of MRI scanning. This case report illustrates the diagnostic and therapeutic dilemma in evaluating and treating acute mandibular swelling following blunt trauma.
\end{abstract}

Keywords: Submandibular; Trauma; Abscess; MRI

\section{Introduction}

Submandibular trauma is rare [1-3], particularly with an intact mandible $[2,3]$. Assessment of a child with a neck mass following trauma requires an assessment of the rapidity of onset of the mass, the presence of constitutional or airway symp-

Manuscript submitted May 24, 2021, accepted August 17, 2021

Published online September 30, 2021

aPaediatrics Department, Blacktown and Mount Druitt Hospitals, Sydney, New South Wales, Australia

bEar, Nose and Throat Department, Sydney Children's Hospital, Sydney, New South Wales, Australia

'Radiology Department, Blacktown and Mount Druitt Hospitals, Sydney, New South Wales, Australia

dEmergency Department, Blacktown and Mount Druitt Hospitals, Sydney, New South Wales, Australia

ePaediatrics and Child Health, Faculty of Medicine, Western Sydney University, Sydney, New South Wales, Australia

${ }^{f}$ Corresponding Author: Stephen Teo, Paediatrics Department, Blacktown and Mount Druitt Hospitals, 75 Railway Street, Mt Druitt, Sydney, NSW 2770,

Australia.Email: s.teo@westernsydney.edu.au

doi: https://doi.org/10.14740/ijcp442 toms, associated maxillofacial or dental trauma, and the main anatomic delineation being whether the mass is lateral or midline. The clinical assessment and blood workup may need to be supplemented by diagnostic imaging. Ultrasound, computed tomography (CT) scanning and magnetic resonance imaging (MRI) scanning may all have a role to play for selected patients [4]. The optimal management of a submandibular abscess in this setting is unclear, but an initially conservative approach with antibiotic therapy is recommended [4] depending on the speed of progression, associated symptoms, and other identified injuries. Surgical management of abscesses is reserved for cases that are refractory to medical management and showing signs of spread particularly to the deeper neck spaces, risking airway obstruction. We report a case of submandibular hematoma with a secondarily infected collection related to trauma in which the diagnosis was facilitated by the availability of MRI scanning.

\section{Case Report}

A previously well 10-year-old girl of Pacific Islander background presented to a peripheral emergency department with a 2-day history of gradually worsening right-sided mandibular swelling, erythema, and reduced mouth opening, following a fall in which she landed on her right jaw onto concrete. There were no other symptoms, and she was systemically well. She was not receiving any medications. Immunizations were complete for her age. Prior to the injury, she had never had a swelling in the facial region. There was no history of dental problems, or previous surgery. Family history was unremarkable.

Observations on presentation showed a heart rate of 115 beats $/ \mathrm{min}$, respiratory rate of 18 breaths $/ \mathrm{min}$, blood pressure of $112 / 87 \mathrm{~mm} \mathrm{Hg}$, oxygen saturation in air of $99 \%$ and temperature of $37.9^{\circ} \mathrm{C}$, rising to $38.2{ }^{\circ} \mathrm{C}$. The patient was alert, and cooperative, comfortable at rest with no respiratory distress or signs of airway compromise. No skin changes in the neck were present. There was a mildly tender single firm $8 \times 10 \mathrm{~cm}$ mass extending from the right ear superiorly, to the sternocleidomastoid posteriorly, to the level of the thyroid cartilage inferiorly. This mass did not cross the midline and there was no palpable cervical lymphadenopathy (Fig. 1). Mouth opening was limited to approximately one finger width. Her occlusion was normal and there was no tenderness of the temporomandibular joints. Tonsils were mildly enlarged but not erythematous, and there were no dental caries or swelling of the floor of mouth or lateral pharyngeal walls. She had full neck movements and was noted to ambulate in the ward. General examination was otherwise unremarkable. 


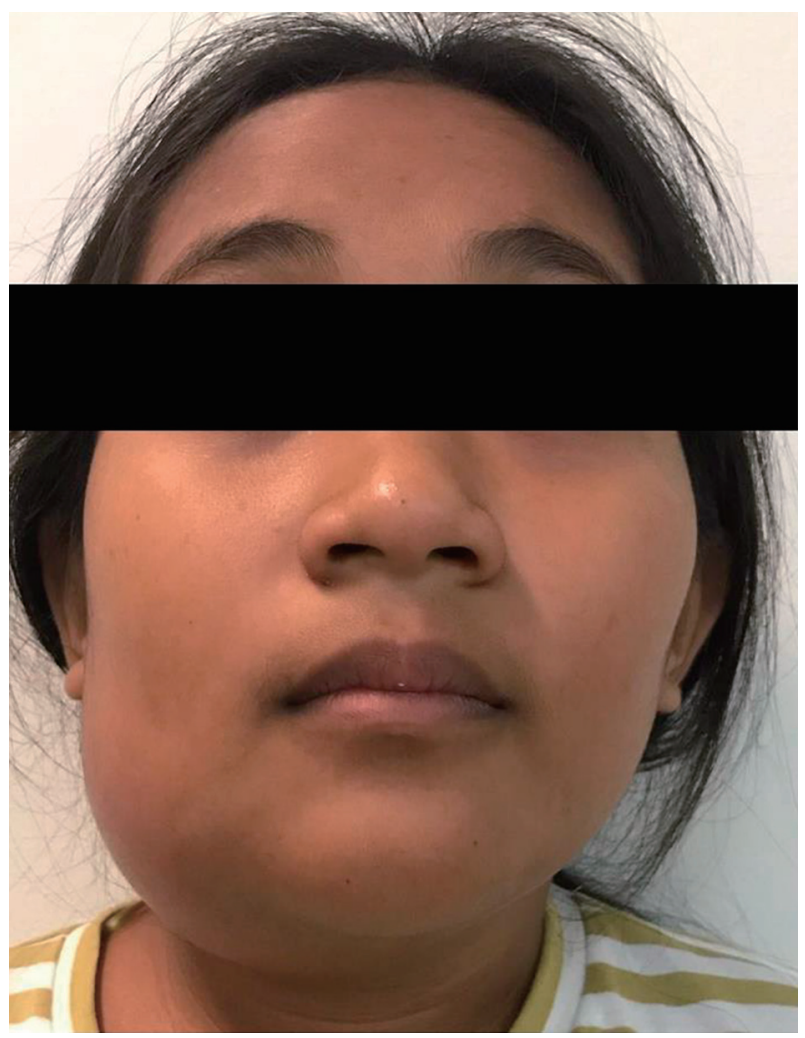

Figure 1. Right lateral neck swelling.

Inflammatory markers were elevated: white cell count (WCC) $18.4 \times 10^{9} / \mathrm{L}\left(3.9-9.9 \times 10^{9} / \mathrm{L}\right)$, neutrophils $14.2 \times$ $10^{9} / \mathrm{L}\left(1.7-5.7 \times 10^{9} / \mathrm{L}\right)$ and C-reactive protein $(\mathrm{CRP}) 60 \mathrm{mg} / \mathrm{L}$ $(\leq 4 \mathrm{mg} / \mathrm{L})$ (Table 1). Intravenous flucloxacillin $(50 \mathrm{mg} / \mathrm{kg} /$ dose, q6h, seven doses) and metronidazole $(10 \mathrm{mg} / \mathrm{kg} / \mathrm{dose}$, q12h, two doses) were administered.

While the option of neck ultrasound was considered, due to the availability of MRI and the clinical assessment that the patient was agreeable and compliant, a non-sedated, noncontrast MRI was performed (Fig. 2) to assess the soft tissue swelling. This showed a fluid collection in the superolateral aspect of the right submandibular salivary gland. The collection was spherical in shape, measuring $16.7 \times 12.6 \mathrm{~mm}$. There was associated inflammation extending into the right masseter muscle, overlying soft tissue edema of the right cheek, and regional reactive lymph nodes. No submandibular or parotid duct dilatation was present. There was no cystic swelling to suggest an underlying lymphatic or vascular malformation and the mandible appeared to be intact. The initial working radiological diagnosis was that of a submandibular abscess. This at the time seemed congruent with the history of fever, tenderness over the mass, and elevated inflammatory markers.

The patient was also commenced on ceftriaxone ( $1 \mathrm{~g}$, single dose) and clindamycin (10 mg/kg/dose, one dose) prior to transfer to a tertiary pediatric hospital for ear, nose, and throat, and oral maxillofacial surgical consultation. At this center, an orthopantogram excluded subclinical odontogenic disease. Two days after the initial MRI, an ultrasound showed a $1 \mathrm{~mL}$ fluid collection in the right submandibular region, bordering on the inferior margin of the body of the mandible. Radiologically it was not possible to distinguish between a hematoma and infection. Laboratory workup 3 days following the initial workup showed a normalization of her total WCC and absolute neutrophil count, and a decrease in her CRP (Table 1).

Fortunately she did not develop airway symptoms as the days progressed and the mass clinically resolved with a conservative approach with oral clindamycin $(10 \mathrm{mg} / \mathrm{kg} / \mathrm{dose}$, $\mathrm{q} 8 \mathrm{~h}, 2$ days) without the need for surgical intervention. The blood culture taken on presentation at the local facility proved negative. Her final presumptive diagnosis was of a post-traumatic hematoma with a secondarily infected collection. She was discharged on the same dosing of oral clindamycin for 5 days. Follow-up had been scheduled for a week post-discharge; however, the patient did not present.

\section{Discussion}

We report a case of a 10-year-old girl with a blunt injury following a fall who presented with a fever and a large lateral neck swelling. Inflammatory markers were raised. An MRI led to an initial working diagnosis of a submandibular abscess. A subsequent ultrasound could not radiologically differentiate infection from a collection. The final diagnosis was a submandibular post-traumatic hematoma with a secondarily infected collection. This case report illustrates the diagnostic and therapeutic dilemma in evaluating and treating acute mandibular swelling following blunt trauma.

Salivary gland injury is uncommon, and injury to the submandibular gland much less common than injury to the parotid gland due to the protection of the former by the mandible [1, 5]. Case reports of submandibular trauma in adults have involved a fishbone [6], motor vehicle accidents [3, 7-9], and gunshot wounds $[2,10]$. Blunt trauma causing submandibular gland injury, also following a fall, has been described in an adult [11]. CT with contrast has been utilized [2, 3, 8, 9]. There are even fewer case reports in young children. A case from almost 60 years ago, published in 1963, of a 3-year-old child with a mandibular fracture was postulated to have involved trauma to a minor salivary gland [12]. A further case of an 8 -year-old child with a submandibular traumatic fistula following an electrical injury and skin grafting was described in 1976 [13]. Both of these cases predated modern imaging techniques. More recently the CT-assisted diagnosis of submandibular fracture following blunt trauma in a 6-year-old child was described [14].

Submandibular abscesses are uncommon but have been described in adults with diabetes mellitus, with [15] or without odontogenic infections [16], which appear to be a predisposing factor [17]. In the pediatric age group, submandibular abscesses are also uncommon. There are case reports in preterm [10, 18-21] and term neonates [22-25]. Cases in older children have been described less frequently in the literature, and have been idiopathic [26] or related to a foreign body [27]. Children may be at lower risk of such abscesses than adults due to a lower prevalence of immunosuppression and odontogenic disease. Clinical features include fever, dysphagia, and a sub- 
Table 1. Laboratory Data at Presentation and 3 Days Following the Initial Workup

\begin{tabular}{|c|c|c|c|c|}
\hline & & esentation & & ay 3 \\
\hline & Values & Reference range & Values & Reference range \\
\hline Hemoglobin & $123 \mathrm{~g} / \mathrm{L}$ & $115-158 \mathrm{~g} / \mathrm{L}$ & $136 \mathrm{~g} / \mathrm{L}$ & $113-143 \mathrm{~g} / \mathrm{L}$ \\
\hline Platelets & $336 \times 10^{9} / \mathrm{L}$ & $150-400 \times 10^{9} / \mathrm{L}$ & $450 \times 10^{9} / \mathrm{L}$ & $187-415 \times 10^{9} / \mathrm{L}$ \\
\hline Hematocrit & $0.37 \mathrm{~L} / \mathrm{L}$ & $0.36-0.46 \mathrm{~L} / \mathrm{L}$ & $0.40 \mathrm{~L} / \mathrm{L}$ & $0.33-0.41 \mathrm{~L} / \mathrm{L}$ \\
\hline Red cell distribution width & $13.9 \%$ & $11.0-15.0 \%$ & $13.4 \%$ & $12.0-14.1 \%$ \\
\hline Neutrophils absolute & $14.2 \times 10^{9} / \mathrm{L}$ & $1.7-5.7 \times 10^{9} / \mathrm{L}$ & $5.70 \times 10^{9} / \mathrm{L}$ & $1.8-7.6 \times 10^{9} / \mathrm{L}$ \\
\hline Lymphocytes absolute & $2.8 \times 10^{9} / \mathrm{L}$ & $1.4-3.8 \times 10^{9} / \mathrm{L}$ & $3.10 \times 10^{9} / \mathrm{L}$ & $1.7-4.5 \times 10^{9} / \mathrm{L}$ \\
\hline Monocytes absolute & $1.4 \times 10^{9} / \mathrm{L}$ & $0.2-1.3 \times 10^{9} / \mathrm{L}$ & $0.5 \times 10^{9} / \mathrm{L}$ & $0.2-0.9 \times 10^{9} / \mathrm{L}$ \\
\hline Potassium & $3.6 \mathrm{mmol} / \mathrm{L}$ & $3.3-4.9 \mathrm{mmol} / \mathrm{L}$ & $4.8 \mathrm{mmol} / \mathrm{L}$ & $3.6-5.3 \mathrm{mmol} / \mathrm{L}$ \\
\hline Chloride & $105 \mathrm{mmol} / \mathrm{L}$ & $97-110 \mathrm{mmol} / \mathrm{L}$ & $100 \mathrm{mmol} / \mathrm{L}$ & $97-110 \mathrm{mmol} / \mathrm{L}$ \\
\hline Bicarbonate & $25 \mathrm{mmol} / \mathrm{L}$ & $20-32 \mathrm{mmol} / \mathrm{L}$ & $26 \mathrm{mmol} / \mathrm{L}$ & $20-32 \mathrm{mmol} / \mathrm{L}$ \\
\hline Urea & $2.7 \mathrm{mmol} / \mathrm{L}$ & $2.0-6.5 \mathrm{mmol} / \mathrm{L}$ & $2.3 \mathrm{mmol} / \mathrm{L}$ & $3.0-7.0 \mathrm{mmol} / \mathrm{L}$ \\
\hline Creatinine & $35 \mu \mathrm{mol} / \mathrm{L}$ & $27-58 \mu \mathrm{mol} / \mathrm{L}$ & $37 \mu \mathrm{mol} / \mathrm{L}$ & $27-58 \mu \mathrm{mol} / \mathrm{L}$ \\
\hline C-reactive protein & $60 \mathrm{mg} / \mathrm{L}$ & $\leq 4 \mathrm{mg} / \mathrm{L}$ & $11 \mathrm{mg} / \mathrm{L}$ & $<3 \mathrm{mg} / \mathrm{L}$ \\
\hline
\end{tabular}

mandibular mass which may be painful, erythematous, and/ or fluctuant; raised inflammatory markers may also be seen [21-23, 26, 28-30].

A suddenly appearing soft tissue mass in the submandibular region is usually inflammatory in etiology [31]. The differential diagnoses include infection of the submandibular gland,

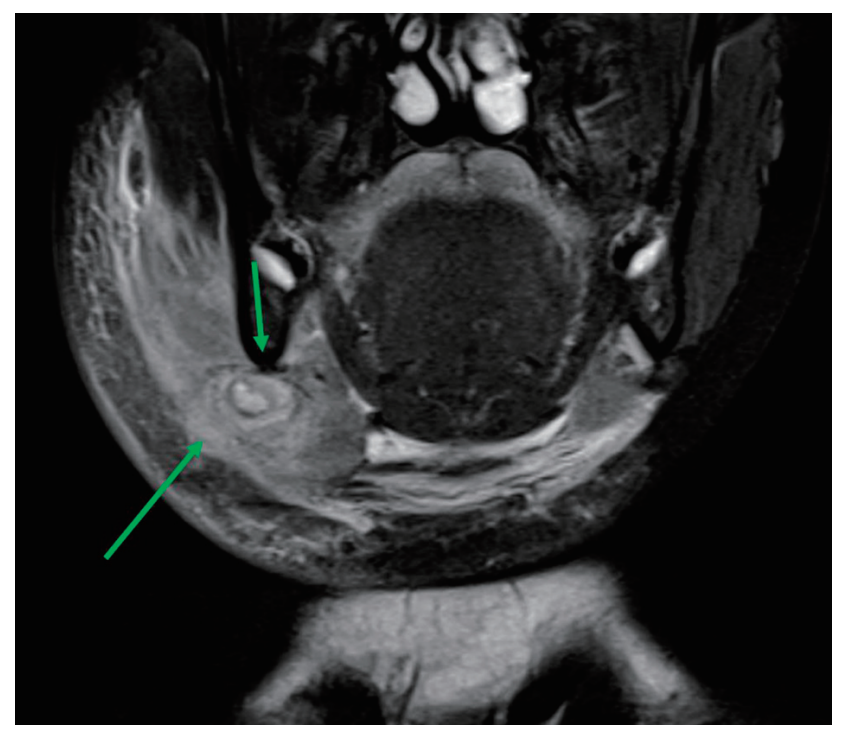

Figure 2. Coronal magnetic resonance imaging of head and neck with collection (green arrows). inflammatory lymphadenopathy from a dental source, a hematoma, or inflammation of a previously undiagnosed vascular or lymphatic malformation [31, 32]. Midline neck masses are more usually a thyroglossal cyst or dermoid cyst [31].

Acute submandibular gland swelling can be due to sialolithiasis leading to obstruction of the salivary ducts, bacterial or viral infections, and inflammation caused by radiotherapy or trauma [1]. Trauma causing submandibular gland injury is uncommon given the gland's position in relation to the mandible [1], and soft tissue trauma to this area is highly unusual in the context of an intact mandible [9] as in this case. However, the timing and site of our patient's injury point to trauma as a potential cause of her acute lateral neck swelling in the region of the submandibular gland. Additionally, the localized tenderness and elevated WCC and CRP supported an inflammatory process [32] even in the absence of local erythema or fever.

An important concern to have in cases of acute submandibular swelling is with the airway management of deteriorating patients. Inflammation spreading to the floor of mouth and pretracheal space can cause the tongue to prolapse as well as distort the airway structures. Trismus can indicate involvement of the muscles of mastication. Such trismus may not relax under general anesthesia, making it difficult to safely secure the airway, necessitating an awake fiber-optic intubation if tolerable and even awake tracheostomy in some cases [33]. Additionally an unresponsive secondary infection requiring drainage can be challenging as access to the submandibular area requires attention to the marginal mandibular branch of the 
facial nerve, the lingual and hypoglossal nerves [34].

The American College of Radiology evidence-based guidelines recommend for the child with a neck mass outside of the parotid region or the thyroid, that neck ultrasound, CT with or without contrast, or MRI with or without contrast are all "usually appropriate", that is, "....indicated in the specified clinical scenarios at a favorable risk-benefit ratio for patients" [4]. Ultrasound is usually the first imaging modality in primary care [32] and allows delineation of mass anatomical location, size, consistency and vascularity $[4,31,35]$. Other advantages of ultrasound are availability (depending on operator expertise) and sedation not being required. CT of neck with contrast is recommended for children with possible malignancy, deeper infection when surgery is being considered or if there is concern about the major neck vessels, the submandibular capsule or glandular integrity. Non-contrast CT might still be useful especially in the setting of trauma to assess if the mandible and other facial bones are intact. Shorter scanning times mean that the need for sedation may be reduced or obviated [4]. Recommendations for MRI are similar to those for CT with contrast, that is, for children with possible malignancy or deeper infection when surgery is being considered. MRI of salivary glands is potentially limited by breathing and swallowing-related artefact. However, MRI provides excellent delineation of soft tissue details [36-38].

Disadvantages of MRI relate to the limited resource availability and the need for sedation or anesthesia particularly in younger children or older children with developmental issues. In our patient, with a potentially compromised airway, in a peripheral setting, the implementation of sedation or anesthesia for diagnostic imaging would require careful assembling of airway expertise, or transfer to a higher-level facility.

The differential diagnosis of an acute mass with radiological evidence of a collection in close proximity to the submandibular gland after trauma includes a hematoma $[3,7,8]$, salivary gland disruption with sialocoele or mucocoele formation $[8,39]$, abscess, and exacerbation of an underlying lesion such as a lymphatic or vascular malformation [35]. Developing abscesses in salivary glands form as enhancing collections on CT with contrast $[36,40]$ or MRI, with a diffuse T2 hyperintense signal. Microabscesses and duct dilatation may appear as focal areas of high T2 signal $[20,41]$. However, in cases such as ours when the exact nature of the collection is difficult to delineate, management should also be guided by clinical indicators such as fever, local tenderness, and inflammatory markers.

A range of pathogens have been described for submandibular abscesses in children ranging from Staphylococcus aureus to group A and B Streptococcus species, with anaerobes and polymicrobial cultures being more common in adults with odontogenic pathology [37, 38, 42]. Broad-spectrum coverage is recommended [37], unless therapy can be culture-directed; however, as in our case, often no pathogens are isolated [4244]. A surgical or catheter drainage approach to the management of submandibular abscess $[45,46]$ has been recommended for those rapidly progressing cases or those non-responsive to medical therapy. Both excision of a damaged submandibular gland [1] and an initially conservative approach [11, 14] have been advocated by other authors. However, the rarity of submandibular trauma with a collection means that there are no evidence-based guidelines. In the case we have presented, the post-traumatic submandibular swelling reduced with medical management and further invasive therapy was avoided.

\section{Learning points}

Submandibular abscess is uncommon in general and particularly in children but should be considered in the setting of a history of trauma and clinical examination findings suggestive of inflammation. Ultrasound is often the initial imaging modality; CT scanning is also utilized. MRI can be more informative especially if there is predominantly soft tissue swelling. An initially conservative approach to the management of submandibular trauma may be possible in the absence of other injuries.

\section{Acknowledgments}

None to declare.

\section{Financial Disclosure}

None to declare.

\section{Conflict of Interest}

None to declare.

\section{Informed Consent}

Informed consent was obtained.

\section{Author Contributions}

RJ, MS, AL and SSST have all made substantial critical revisions to the manuscript. All authors read and approved the final manuscript. SSST is accountable for all aspects of the work.

\section{Data Availability}

The authors declare that data supporting the findings of this study are available within the article

\section{References}

1. Lazaridou M, Iliopoulos C, Antoniades K, Tilaveridis I, Dimitrakopoulos I, Lazaridis N. Salivary gland trauma: a review of diagnosis and treatment. Craniomaxillofac Trauma Reconstr. 2012;5(4):189-196. 
2. Liu C, Darian A, Romeus L, Cervantes S, Westmoreland T. Submandibular gland injury with a ball bearing gunshot wound. Cureus. 2020;12(10):e11268.

3. Tonerini M, Fratini L, Grassi L, Ravenna V, Tozzini A, Trincavelli F, Orsitto E. Blunt submandibular gland trauma: acute CT findings. Emerg Radiol. 2002;9(2):116118.

4. Expert Panel on Neurologic Imaging, Aulino JM, Kirsch CFE, Burns J, Busse PM, Chakraborty S, Choudhri AF, et al. ACR appropriateness criteria ${ }^{\circledR}$ neck mass-adenopathy. J Am Coll Radiol. 2019;16(5S):S150-S160.

5. Bialek EJ, Jakubowski W, Zajkowski P, Szopinski KT, Osmolski A. US of the major salivary glands: anatomy and spatial relationships, pathologic conditions, and pitfalls. Radiographics. 2006;26(3):745-763.

6. Iwai T, Sugiyama S, Hayashi Y, Oguri S, Hirota M, Mitsudo K, Tohnai I. Sialendoscopic removal of fish boneinduced sialoliths in the duct of the submandibular gland. Auris Nasus Larynx. 2018;45(2):343-345.

7. Boyd BC, Dattilo DJ, Goth JH, Liberto FJ. An unusual supplemental vehicle restraint-induced injury: report of case and review of literature. J Oral Maxillofac Surg. 2002;60(9):1062-1066.

8. Harbison JM, Page MP. Submandibular gland injury and delayed airway compromise caused by a seat belt. Am J Otolaryngol. 2010;31(3):209-211.

9. Roebker JJ, Hall LC, Lukin RR. Fractured submandibular gland: CT findings. J Comput Assist Tomogr. 1991;15(6):1068-1069.

10. Singh B, Shaha A. Traumatic submandibular salivary gland fistula. J Oral Maxillofac Surg. 1995;53(3):338339.

11. Parsi S, Johnson EJ, Kates MJ. Isolated submandibular gland injury in the setting of blunt trauma. Am Surg. 2013;79(1):E1-2.

12. Traiger J. Laceration of a minor salivary gland. A complicating factor in a fracture of the mandible in a child. Oral Surg Oral Med Oral Pathol. 1963;16:783-785.

13. de Geus JJ, Maisels DO. A traumatic fistula of the submandibular gland. Br J Plast Surg. 1976;29(2):196-198.

14. Aggarwal A, Shaheen H, Blankas-Hernaez N. A 6-yearold female with unilateral cervical swelling. Pediatr Ann. 2015;44(2):56-59.

15. Yamagata K, Takeda M, Onizawa K, Yoshida H. Submandibular abscess caused by Salmonella. Int J Oral Maxillofac Surg. 2006;35(10):969-971.

16. Bahar G, Dansuk Z, Kocaturk S, Cakir T, Mert A. Abscess of the neck caused by Salmonella enteritidis. Otolaryngol Head Neck Surg. 2003;129(4):445-447.

17. Wang LF, Tai CF, Kuo WR, Chien CY. Predisposing factors of complicated deep neck infections: 12-year experience at a single institution. J Otolaryngol Head Neck Surg. 2010;39(4):335-341.

18. Takahashi R, Chikaoka S, Ito T, Yamada M, Matsutani S, Nakae S. Neonatal submandibular suppurative sialadenitis. Eur J Pediatr. 2000;159(11):868.

19. McAdams RM, Mair EA, Rajnik M. Neonatal suppurative submandibular sialadenitis: case report and literature review. Int J Pediatr Otorhinolaryngol. 2005;69(7):993-
997.

20. Garavello W, Romagnoli M, Somigliana E, Zorloni C, Sordo L, Gaini RM. The intriguing association between prematurity and neonatal isolated submandibular suppurative sialadenitis. Int J Pediatr Otorhinolaryngol. 2002;62(1):41-44.

21. Subhani M, Monte DC, Roche P, Parton L. Isolated bilateral submandibular abscesses in a preterm infant: a case report. Int J Pediatr Otorhinolaryngol. 1999;51(1):47-50.

22. Bafaqeeh SA. Complicated neonatal submandibular suppurative sialadenitis. Int J Pediatr Otorhinolaryngol. 1998;44(3):267-271.

23. Bova R, Walker P. Neonatal submandibular sialadenitis progressing to submandibular gland abscess. Int J Pediatr Otorhinolaryngol. 2000;53(1):73-75.

24. Weibel L, Goetschel P, Meier R, Radivojevic V, Berger C. Neonatal suppurative submandibular sialadenitis. Pediatr Infect Dis J. 2005;24(4):379-381.

25. Pereira E, Lapa P, Basto L, Afonso E. Isolated suppurative submandibular sialadenitis in a preterm neonate. BMJ Case Rep. 2014;2014.

26. Ismi O, Ozalp H, Hamzaoglu V, Bucioglu H, Vayisoglu Y, Gorur K. Grisel's syndrome accompanying a submandibular abscess. Braz J Otorhinolaryngol. 2020;86(5):658661.

27. Gonzalez de Alba C, Garcia E, Molina Berganza F, Fergie $\mathrm{J}$. Foreign body as cause of submandibular swelling in an infant. Pediatr Infect Dis J. 2016;35(8):930.

28. Raftopulos M, Jefferson N, Mackay S, Ashford B. A rare case of submandibular abscess complicated by stroke. JRSM Short Rep. 2013;4(12):2042533313505513.

29. Ruskin WJ, Farnad FA, Wolf SM. Bilateral proptosis and jugular vein thrombosis after submandibular abscess. J Oral Maxillofac Surg. 2009;67(3):665-668.

30. Boscolo-Rizzo P, Da Mosto MC. Submandibular space infection: a potentially lethal infection. Int J Infect Dis. 2009;13(3):327-333

31. Meier JD, Grimmer JF. Evaluation and management of neck masses in children. Am Fam Physician. 2014;89(5):353-358.

32. Smith A, Cronin M. Paediatric neck lumps: An approach for the primary physician. Aust J Gen Pract. 2019;48(5):289-293.

33. Bakshi SS. Ludwig's angina. Arch Dis Child. 2016;101(6):545.

34. Batra AP, Mahajan A, Gupta K. Marginal mandibular branch of the facial nerve: An anatomical study. Indian J Plast Surg. 2010;43(1):60-64.

35. King SK. Lateral neck lumps: A systematic approach for the general paediatrician. J Paediatr Child Health. 2017;53(11):1091-1095.

36. Agarwal AK, Kanekar SG. Imaging of submandibular and sublingual salivary glands. Neuroimaging Clin NAm. 2018;28(2):227-243.

37. Lawrence R, Bateman N. Controversies in the management of deep neck space infection in children: an evidence-based review. Clin Otolaryngol. 2017;42(1):156163.

38. Vieira F, Allen SM, Stocks RM, Thompson JW. Deep neck 
infection. Otolaryngol Clin North Am. 2008;41(3):459483.

39. Cholankeril JV, Scioscia PA. Post-traumatic sialoceles and mucoceles of the salivary glands. Clin Imaging. 1993;17(1):41-45.

40. Abdel Razek AAK, Mukherji S. Imaging of sialadenitis. Neuroradiol J. 2017;30(3):205-215.

41. Friedman E, Patino MO, Udayasankar UK. Imaging of pediatric salivary glands. Neuroimaging Clin N Am. 2018;28(2):209-226.

42. Huang CM, Huang FL, Chien YL, Chen PY. Deep neck infections in children. J Microbiol Immunol Infect. 2017;50(5):627-633.
43. Mungul S, Maharaj S. Microbiology of paediatric deep neck space infection. Int J Pediatr Otorhinolaryngol. 2019;123:116-122.

44. Corte FC, Firmino-Machado J, Moura CP, Spratley J, Santos M. Acute pediatric neck infections: Outcomes in a seven-year series. Int J Pediatr Otorhinolaryngol. 2017;99:128-134.

45. Probst FA, Otto S, Sachse R, Cornelius CP. Minimallyinvasive catheter drainage of submandibular abscesses. Br J Oral Maxillofac Surg. 2013;51(7):e199-200.

46. Ardehali MM, Jafari M, Hagh AB. Submandibular space abscess: a clinical trial for testing a new technique. Otolaryngol Head Neck Surg. 2012;146(5):716-718. 